\title{
Design, Synthesis, And Evaluation Of Cyanopyridines As Anti-Colorectal Cancer Agents Via Inhibiting STAT3 Pathway
}

This article was published in the following Dove Press journal: Drug Design, Development and Therapy

Lingyuan $\mathrm{Xu},{ }^{1-3, *}$ Lingxi Shi, ${ }^{1-3, *}$ Sensen Qiu, ${ }^{4, *}$ Siyu Chen, ${ }^{1-3}$ Mengsha Lin, ${ }^{1-3}$ Youqun Xiang,' Chengguang Zhao, (D) ${ }^{3}$ Jiandong Zhu, ${ }^{2}$ Liqun Shen, ${ }^{4}$ Zhigui Zuo ${ }^{1,2}$

'Department of Colorectal Surgery, The First Affiliated Hospital, Wenzhou Medical University, Wenzhou, Zhejiang 325000, People's Republic of China; ${ }^{2}$ Department of Surgical Oncology, Affiliated Yueqing Hospital, Wenzhou Medical University, Wenzhou, Zhejiang 325600, People's Republic of China;

${ }^{3}$ Cancer and Anticancer Drug Research Center, School of Pharmaceutical Sciences, Wenzhou Medical University, Wenzhou, Zhejiang 325035, People's Republic of China; ${ }^{4}$ Department of Pharmaceutical Sciences, College of Chemistry and Chemical Engineering, Guangxi University for Nationalities, Nanning 530006, People's Republic of China

*These authors contributed equally to this work

Correspondence: Liqun Shen Department of Pharmaceutical Sciences, College of Chemistry and Chemical Engineering, Guangxi University for Nationalities, Nanning 530006, People's Republic of China

Tel +86 77I 3267019

Email liqunshen@I26.com

Zhigui Zuo

Department of Colorectal Surgery, The First Affiliated Hospital, Wenzhou Medical University, Wenzhou, Zhejiang 325000,

People's Republic of China

Tel +8657786699057

Email zuozg007@I26.com
Background: Colorectal cancer is one of the common malignant tumors. Cyanopyridine and aminocyanopyridine having a carbon-nitrogen bond have been shown to have significant anticancer effects. STAT3 is a promising therapeutic target in multiple cancers. However, there are currently no effective STAT3 inhibitors in clinical practice for the treatment of colorectal cancer.

Materials and methods: We screened 27 cyanopyridines for their anticancer activity by cell viability. The HCT-116, RKO, and DLD-1 cell lines were used to evaluate the anticolorectal cancer effect of $3 \mathrm{n}$. Scratch experiments and colony formation assays were used for the assessment of cell migration and proliferation capacity. Phosphorylated STAT3, STAT3, MCL-1, and Survivin levels were assessed by Western blot analysis.

Results: In this study, we synthesized 27 cyanopyridines and screened their anticancer activities in three human tumor cells, HCT-116, Hela229, and A375. We found that 2amino-3-cyanopyridine $3 \mathrm{n}$ has better anticancer activity with IC50 values in the low micromolar range. Furthermore, $3 \mathrm{n}$ significantly inhibited the migration and colony formation of colorectal cancer cells. Mechanistically, $3 \mathrm{n}$ inhibited the expression of STAT3 phosphorylation in a dose- and time-dependent manner.

Conclusion: $3 \mathrm{n}$ is worth of further investigations toward the discovery of STAT3 inhibitor as a drug candidate for cancer therapy.

Keywords: design, cyanopyridine, colorectal cancer, STAT3, inhibitor

\section{Introduction}

Colorectal cancer is one of the common malignant tumors in our digestive system, and the morbidity and mortality rate are increasing year by year. ${ }^{1-3}$ At present, the main treatment for colorectal cancer is surgical treatment, combined with radiotherapy and chemotherapy, but surgery alone may not be cured. ${ }^{4}$ Drug treatment of colorectal cancer often has drug resistance, leading to a reduction in colorectal cancer survival rate for cancer treatment. ${ }^{5}$ Signal transduction and transcriptional activator (STAT3) is defined as an essential oncogene that regulates cancer cell proliferation, apoptosis, and metastasis. ${ }^{6,7}$ To a large extent, STAT3 is considered to be one of the key oncogenes and a key therapeutic target, so inhibition of aberrant activation of STAT3 in colorectal cancer may be a promising strategy. ${ }^{5,8,9}$ However, to date there have been no clinically useful STAT3 inhibitors for the treatment of cancer. ${ }^{1,10,11}$

There are many reports on the anti-tumor activity of 2-amino-3-cyanopyridines, but the results are not satisfactory. ${ }^{12}$ So far, none of these compounds have entered 
clinical research, and the structure-activity relationship of the system has not been given. ${ }^{13-15}$ There are relatively few reports on 3-amino-3-cyanopyridine compounds compared to 2-amino-3-cyanopyridine compounds, and there are few studies on the anti-tumor activity of such compounds. $^{16}$ Our group has previously demonstrated that the aminocyanopyridines exhibit significant antitumor activity against lung cancers in vitro and in vivo. ${ }^{17}$ So we continued our previous studies to further design, synthesize and evaluate the in vitro anticancer activity of a series of aminocyanopyridines.

\section{Materials And Methods}

\section{Antibodies And Reagents}

The antibodies against P-STAT3, STAT3, and GAPDH were purchased from Cell Signal Technology (Danvers, MA, USA). The horseradish peroxidase (HRP)-conjugated donkey anti-rabbit IgG and HRP-conjugated goat anti-mouse IgG were purchased from Santa Cruz Biotechnology Inc. (Dallas, TX, USA). Methylthiazolyldiphenyl-tetrazolium bromide (MTT) and dimethyl sulfoxide (DMSO) were purchased from Sigma-Aldrich Co. (St Louis, MO, USA). The caspase-3 colorimetric assay kit was purchased from Abcam Co. (Cambridge, MA, USA). A Bradford proteinassay kit, polyvinylidene fluoride membrane, and enhanced chemiluminescence kit were obtained from Bio-Rad Laboratories (Hercules, CA, USA). A protease phosphatase-inhibitor mixture was obtained from Applygen Technologies (Beijing, People's Republic of China). Acrylamide (30\%), coomassie brilliant blue, tetramethylethylenediamine, tris-glycine, sodium dodecyl sulfate, prestained protein marker, and nonfat dry milk were from Bio-Rad Laboratories.

\section{Chemistry}

Reactions were monitored by thin-layer chromatography on silica gel plates (HSGF 254), visualizing with ultraviolet. All the melting points are obtained uncorrected and were taken in a Microscope Melting Point X-6 (Beijing Tech, Beijing, People's Republic of China). ${ }^{1} \mathrm{H}$ NMR and ${ }^{13} \mathrm{C}$ NMR spectroscopy were determined in Bruker ACANCE III HD-400 and 100 spectrometers (Bruker, Karlsruhe, Germany), respectively. Using DMSO-d6, acetone and $\mathrm{CDCl}_{3}$ solution with TMS as an internal standard. The following abbreviations mean spin multiplicities: singlet (S), doublet (D), triplet (T), and multiplet (M). IR spectra were recorded on a Fourier transform infrared (FTIR) spectrometer MAGNA-IR 550 (Thermo Electron Corporation, MMAS, USA) using $\mathrm{KBr}\left(v \mathrm{~cm}^{-1}\right)$. High resolution mass spectrometry (HRMS) were determined on LC-MS QE Focus (Thermo Fisher Scientific, MMAS, USA). Column chromatography was performed on silica gel (200-300 mesh) from Qingdao Ocean Chemicals (Qingdao, Shandong, People's Republic of China) using distilled petroleum ether and ethyl acetate as mobile phase. Analytical HPLC analyses were performed on Agilent 1260 liquid chromatograph fitted with an InertexC18 column, with the purity of compounds $>95 \%$. All the materials were obtained from commercially available sources and used without further purification, unless otherwise specified. Yields were not optimized.

\section{Cell Culture}

Cell culture and human colorectal cell lines HCT-116, RKO, and DLD-1 were purchased from Shanghai cell bank. All of the above cells were cultured in Roswell Park Memorial Institute (RPMI)-1640 media (Thermo Fisher Scientific, Waltham, MA, USA), containing 10\% FBS (Gibco, NY, USA) and were maintained at $37^{\circ} \mathrm{C}$ in a humidified chamber with $5 \% \mathrm{CO}_{2}$.

\section{Cell Viability Assay In Vitro}

Approximately $1 \times 10^{3}$ cells, suspended in 1640 medium, were plated onto each well of a 96-well plate and incubated in $5 \% \mathrm{CO}_{2}$ at $37^{\circ} \mathrm{C}$ for $24 \mathrm{hrs}$. The test compounds at indicated final concentrations were added to the culture medium and the cell cultures were continued for $72 \mathrm{hrs}$. Fresh MTT was added to each well at a terminal concentration of $5 \mathrm{mg} / \mathrm{mL}$ and incubated with cells at $37^{\circ} \mathrm{C}$ for 4 hrs. The formazan crystals were dissolved in $150 \mathrm{~mL}$ DMSO each well, and the absorbency at $490 \mathrm{~nm}$ (for absorbance of MTT formazan) and $630 \mathrm{~nm}$ (for the reference wavelength) was measured with the ELISA reader. All the compounds were tested three times in each of the cell lines. The results expressed as IC50 (inhibitory concentration $50 \%$ ) were the averages of three determinations and calculated by using the GraphPad Prism 6 software.

\section{Colony Formation Assay}

The untreated human colorectal cancer cells were plated in 6 well plates at a density of 1000 cells per well. After 7-10 days, the cells were fixed with $4 \%$ paraformaldehyde for 10-15 mins, colonies were stained with crystal violet for 15 mins at room temperature. 


\section{Cell Migration Assay}

RKO and DLD-1 cells were seeded into 6 well plates at a density of $2 \times 10^{5}$ cells per well and cultured to $90 \%$ confluence. Then, the culture area was scratched with a sterile crystal pipette tip to make a linear gap in the confluent cell monolayer. The suspended cells were washed gently with PBS. Finally, cells were observed under an inverted microscope, cells were allowed to fill the gap and images of the culture area were captured at $0 \mathrm{hr}, 24 \mathrm{hrs}$ and $48 \mathrm{hrs}$ after scratches. Three independent assays were performed.

\section{Western Blot Analysis}

The colorectal cells were lysed with RIPA lysis buffer with protease inhibitor (Boster, Wuhan, People's Republic of China) and the protein concentration was determined after centrifugation at $12,000 \mathrm{rpm}$ at $4^{\circ} \mathrm{C}$ for 10 mins. Supernatants collected, in order to determine total protein concentration, and protein concentrations assessed using a Bradford protein assay. The PVDF membrane was used to transfer proteins, and the blots were blocked for 90 mins at room temperature with fresh $5 \%$ nonfat milk in TBST, then the membrane with the specific primary antibody was incubated at $4^{\circ} \mathrm{C}$ overnight and at room temperature for 60 mins with the secondary antibody. Finally, the Image J software were used to quantify the bands.

\section{Statistical Analysis}

Statistics were performed using GraphPad Prism software (GraphPad, San Diego, CA, USA). The differences between sets of data were made using the Student's $t$ test. The results are expressed as mean \pm SE. $P<0.05$ was statistically significant.

\section{Results}

\section{General Procedure For The Compounds 3a-3o (Scheme I)}

A mixture of the substituted acetophenone $(1 \mathrm{mmol})$, together with the respective benzaldehyde $(1 \mathrm{mmol})$, malononitrile $(1 \mathrm{mmol})$, and ammonium acetate $(8 \mathrm{mmol})$ in toluene $(10 \mathrm{~mL})$ was stirred at reflux for $8-12 \mathrm{hrs}$. After cooling to room temperature, the mixture was diluted ethyl acetate and THF. The organic phase was washed twice with brine, dried over $\mathrm{Na}_{2} \mathrm{SO}_{4}$, the filtrate and concentrated under reduced pressure. The residue was suspended in absolute ethanol. The precipitate was collected by filtration and purified by silica gel column chromatography to give the desired product.

\section{2-Amino-6-(4-hydrophenyl)-4-(4- bromophenyl) nicotinonitrile (3a)}

White floccule. mp: $304-307^{\circ} \mathrm{C} .{ }^{1} \mathrm{H}$ NMR (400 MHz, DMSO, $\delta$ ppm): 12.91 (s, 1H), 7.71-7.86 (m, 8H), $6.90(\mathrm{~s}, 1 \mathrm{H}) .{ }^{13} \mathrm{C}$ NMR (100MHz, DMSO-d6, $\delta$ ppm): 154.03, 149.28, 143.97, $136.83,133.05,132.15,131.24,123.73,119.50,116.15$, 115.77, 105.10, 96.30, 95.25. IR (KBr) $\sigma / \mathrm{cm}^{-1}: 3456.77$, $3349.12,2205.78,1620.41,1594.70,1574.30,1545.15$, $1519.76,1492.04,1456.67,1363.68,1231.16,1172.41$, 805.80. HR-ESI-MS (pos. ion mode): $\mathrm{m} / \mathrm{z}=366.0061[\mathrm{M}+\mathrm{H}]^{+}$ (anal. calcd. for $\mathrm{C}_{18} \mathrm{H}_{12} \mathrm{BrN}_{3} \mathrm{O}=365.0164$ ).

\section{2-Amino-4, 6-Bis-(4-bromophenyl) nicotinonitrile (3b)}

White cottony. mp: $279-280^{\circ} \mathrm{C} .{ }^{1} \mathrm{H}$ NMR $(400 \mathrm{MHz}$, DMSO-d6, $\delta \mathrm{ppm}): 8.11(\mathrm{~m}, 1 \mathrm{H}), 8.08(\mathrm{~m}, 1 \mathrm{H}), 7.78(\mathrm{~d}$, $\mathrm{J}=2.0 \mathrm{~Hz}, 1 \mathrm{H}), 7.76(\mathrm{~m}, 1 \mathrm{H}), 7.72(\mathrm{~m}, 1 \mathrm{H}), 7.69(\mathrm{~m}, 1 \mathrm{H})$, $7.66(\mathrm{~m}, 1 \mathrm{H}), 7.64(\mathrm{~d}, \mathrm{~J}=2.0 \mathrm{~Hz}, 1 \mathrm{H}), 7.32(\mathrm{~s}, 1 \mathrm{H}$, cyanopyridine), 7.11 (s, 2H, amidogen). ${ }^{13} \mathrm{C}$ NMR (101 MHz, DMSO-d6, $\delta$ ppm): 161.25, 157.95, 154.37, 137.09, $136.50,132.17,132.11,131.03,129.77,124.40,123.77$, 109.47, 87.25. IR (KBr) $\sigma / \mathrm{cm}^{-1}: 3494.14,3389.24$, $2205.50,1607.41,1580.65,1543.00,1489.62,1454.13$, 1392.56, 1431.69, 1364.77, 1073.69, 1009.54, 818.44. HR-ESI-MS (pos. ion mode): $\mathrm{m} / \mathrm{z}=429.9371[\mathrm{M}+\mathrm{H}]^{+}$ (anal. calcd. for $\mathrm{C}_{18} \mathrm{H}_{11} \mathrm{Br}_{2} \mathrm{~N}_{3}=428.9299$ ).

\section{2-Amino-6-(5-fluoro-2-benzyloxy)-4-(4- bromophenyl) nicotinonitrile (3c)}

Belge power. mp: $235-237^{\circ} \mathrm{C} .{ }^{1} \mathrm{H}$ NMR $(400 \mathrm{MHz}$, DMSO-d6, $\delta$ ppm): 7.71-7.72 (m, 1H), 7.69-7.70 (q, J $=2.2 \mathrm{~Hz}, 1 \mathrm{H}), 7.64-7.65(\mathrm{~m}, 1 \mathrm{H}), 7.42-7.44(\mathrm{dd}, \mathrm{J}=7.7$, $1.5 \mathrm{~Hz}, 2 \mathrm{H}), 7.26-7.38(\mathrm{~m}, 8 \mathrm{H}), 7.05$ (s, 2H), 5.15 (s, 2H, benzyloxy). ${ }^{13} \mathrm{C}$ NMR (100MHz, DMSO-d6, $\delta$ ppm): $161.07,156.49,153.52,153.01,136.83,136.49,132.16$, $130.56,128.94,128.69,128.57,123.58,117.68,117.18$, $117.13,115.47,114.09,86.74,71.30$. IR $(\mathrm{KBr}) \sigma / \mathrm{cm}^{-1}$ : 3470.51, 3319.99, 2919.08, 2206.72, 1648.36, 1572.28, $1544.44,1501.00,1452.65,1426.09,1253.56,823.97$, 727.52. HR-ESI-MS (pos. ion mode): $\mathrm{m} / \mathrm{z}=474.0619[\mathrm{M}$ $+\mathrm{H}]^{+}$(anal. calcd. for $\mathrm{C}_{25} \mathrm{H}_{17} \mathrm{BrFN}_{3} \mathrm{O}=473.0539$ ).

\section{2-Amino-6-(2, 4-bisbenzyloxy)-4-(4- bromophenyl) nicotinonitrile (3d)}

White cottony power. mp: $170-171^{\circ} \mathrm{C} .{ }^{1} \mathrm{H}$ NMR $(400 \mathrm{MHz}$, DMSO-d6, $\delta$ ppm): 7.92 (d, J=8.6Hz, 1H), 7.64 (d, J=7.7 


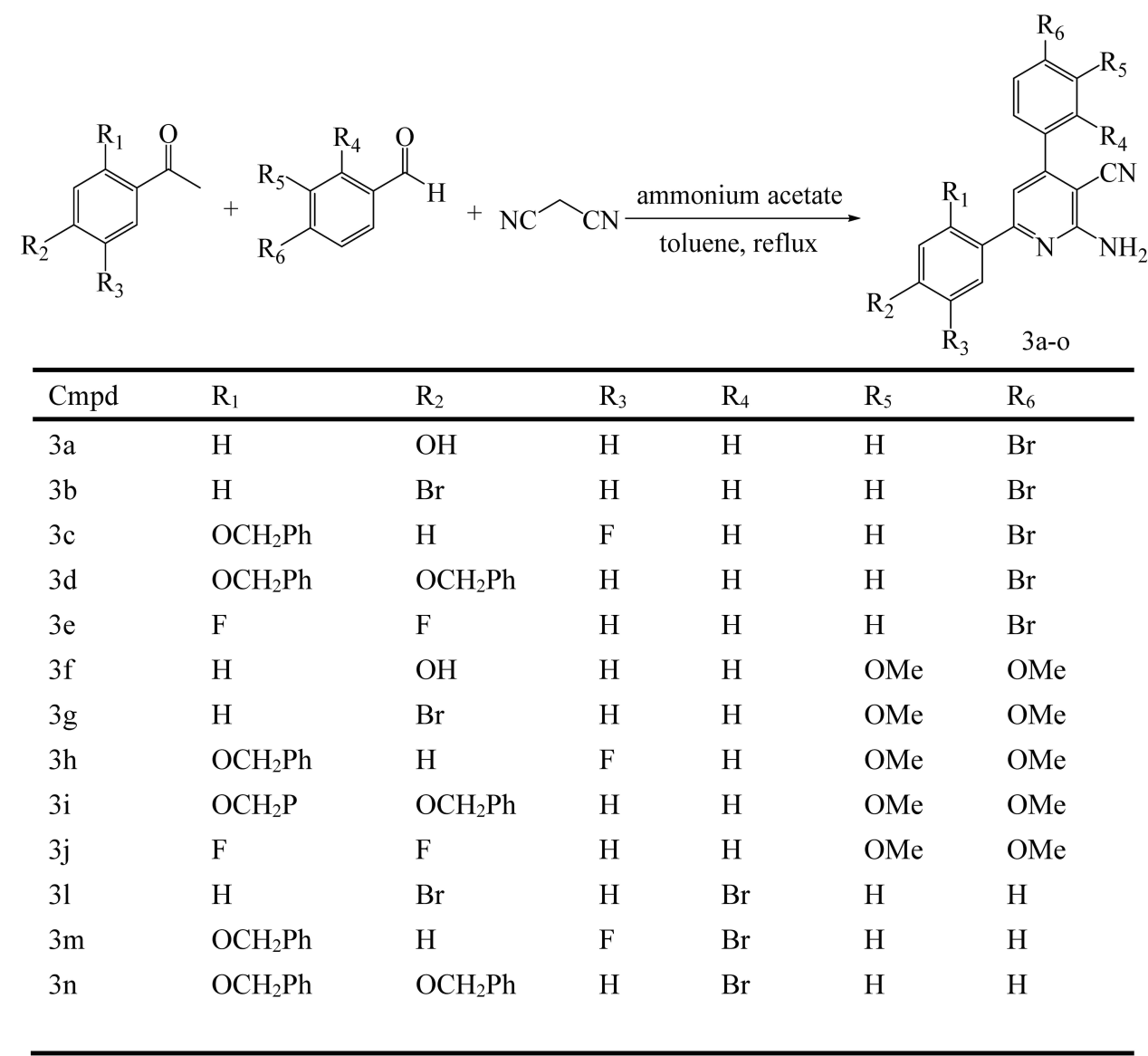

Scheme I The designed route of the 2-amino-cyanopyridines and the chemical structure of the compound 3a-n.

$\mathrm{Hz}, 2 \mathrm{H}), 7.49-7.36(\mathrm{~m}, 10 \mathrm{H}), 7.25$ (d, J=9.0Hz, 3H), 6.93 (s, 3H), 6.79 (d, J=8.7Hz, 1H, cyanopyridine), 5.18 (d, $\mathrm{J}=16.3 \mathrm{~Hz}, 4 \mathrm{H}$, benzyloxy). ${ }^{13} \mathrm{C}$ NMR $(100 \mathrm{MHz}$, DMSOd6, $\delta$ ppm): $161.53,161.05,158.44,157.73,152.50,137.19$, $136.84,136.77,132.43,132.10,130.52,128.97,128.75$, $128.58,128.47,128.37,123.38,120.00,113.70,107.26$, 100.96, 85.26, 70.74, 70.00. IR (KBr) $\sigma / \mathrm{cm}^{-1}: 3453.09$, $3289.25,3153.39$, 2205.43, 1637.18, 1603.08, 1573.97, $1544.55,1506.81,1492.87,1452.29,1302.11,1257.08$, $1179.88,1132.98,1026.70,822.96,737.94,694.70$. HRESI-MS (pos. ion mode): $\mathrm{m} / \mathrm{z}=564.1107[\mathrm{M}+\mathrm{H}]^{+}$(anal. calcd. for $\mathrm{C}_{32} \mathrm{H}_{24} \mathrm{BrN}_{3} \mathrm{O}_{2}: 563.1031(97.3 \%)$ ).

\section{2-Amino-6-(2, 4-bisfluoro)-4-(4-} bromophenyl) nicotinonitrile (3e)

Belge power. mp: $235-238^{\circ} \mathrm{C} .{ }^{1} \mathrm{H}$ NMR $(400 \mathrm{MHz}$, DMSO-d6, $\delta$ ppm): 7.76-7.47 (m, 6H), 7.30 7.26 $(\mathrm{m}, 1 \mathrm{H}), 6.99(\mathrm{~d}, \mathrm{~J}=23.6 \mathrm{~Hz}, 2 \mathrm{H}), 6.82(\mathrm{~s}, 1 \mathrm{H}$, cyanopyridine) ${ }^{13} \mathrm{C} \quad$ NMR $\quad(100 \quad \mathrm{MHz}, \quad$ DMSO-d6, $\delta \mathrm{ppm}): 154.03,149.26,143.96,136.83,133.00,132.15$,
131.22, 123.73, 119.51, 116.14, 115.76, 96.34, 95.28. IR (KBr) $\sigma / \mathrm{cm}^{-1}: \quad 3458.51,3360.33,3238.35,2217.85$, 1643.64, 1593.06, 1512.73, 1286.61, 1102.15, 813.55. HR-ESI-MS (pos. ion mode): $\mathrm{m} / \mathrm{z}=386.0102[\mathrm{M}$ $+\mathrm{H}]^{+}$(anal. calcd. for $\mathrm{C}_{18} \mathrm{H}_{10} \mathrm{BrF}_{2} \mathrm{~N}_{3}: 385.0026$ ).

\section{2-Amino-6-(4-hydroxyphenyl)-4-(3,} 4-dimethoxyphenyl) nicotinonitrile (3f)

Yellow power. mp: $155-156{ }^{\circ} \mathrm{C} .{ }^{1} \mathrm{H}$ NMR $(400 \mathrm{MHz}$, DMSO-d6, $\delta \mathrm{ppm}): 9.91(\mathrm{~s}, 1 \mathrm{H}), 8.01(\mathrm{~d}, \mathrm{~J}=8.5 \mathrm{~Hz}$, 2H), 7.28-7.08 (m, 4H), 6.93-6.73 (m, 4H), $3.84(\mathrm{~d}$, $\mathrm{J}=5.5 \mathrm{~Hz}, 6 \mathrm{H}$, methoxy). ${ }^{13} \mathrm{C}$ NMR $(100 \mathrm{MHz}$, DMSOd6, $\delta \mathrm{ppm})$ : $161.35,159.96,158.90,154.75,150.39$, 149.07, 129.88, 129.42, 128.92, 121.46, 115.83, 112.46, 112.12, 108.51, 85.63, 56.11. IR (KBr) $\sigma / \mathrm{cm}^{-1}: 3465.71$, 2923.19, 2201.05, 1640.74, 1610.51, 1575.25, 1546.32, 1513.00, 1260.11, 1207.93, 1207.93, 1170.39, 1130.99, 1021.82, 835.97. HR-ESI-MS (pos. ion mode): $\mathrm{m} /$ $\mathrm{z}=346.1202 \quad[\mathrm{M}-\mathrm{H}]^{+}$(anal. calcd. for $\mathrm{C}_{20} \mathrm{H}_{17} \mathrm{~N}_{3} \mathrm{O}_{3}$ : 347.1270). 


\section{2-Amino-6-(4-bromophenyl)-4-(3,}

4-dimethoxyphenyl) nicotinonitrile (3g)

Brown power. mp: $125-127^{\circ} \mathrm{C} .{ }^{1} \mathrm{H}$ NMR $(400 \mathrm{MHz}$, DMSO-d6, $\delta \mathrm{ppm}): 8.10(\mathrm{~d}, \mathrm{~J}=6.9 \mathrm{~Hz}, 2 \mathrm{H}), 7.71(\mathrm{~d}$, $\mathrm{J}=6.9 \mathrm{~Hz}, 2 \mathrm{H}), 7.30(\mathrm{~d}, \mathrm{~J}=16.3 \mathrm{~Hz}, 3 \mathrm{H}), 7.14(\mathrm{~s}, 1 \mathrm{H}$, cyanopyridine), 7.02 (s, 2H), $3.79(\mathrm{~d}, \mathrm{~J}=38.2 \mathrm{~Hz}, 6 \mathrm{H}$, methoxy).${ }^{13} \mathrm{C}$ NMR (100 MHz, DMSO-d6, $\left.\delta \mathrm{ppm}\right)$ : $161.38,157.59,155.34,150.54,149.08,137.30,132.06$, $129.75,129.50,124.20,121.61,117.78,112.51,112.11$, 109.48, 87.31, 56.13, 56.11. IR (KBr) $\sigma / \mathrm{cm}^{-1}:$ 3461.49, 2920.00, 2200.00, 1607.93, 1506.78, 1256.78, 1173.55, 1024.79, 837.36. HR-ESI-MS (pos. ion mode): $\mathrm{m} /$ $\mathrm{z}=410.0516[\mathrm{M}+\mathrm{H}]^{+}$(anal. calcd. for $\mathrm{C}_{20} \mathrm{H}_{16} \mathrm{BrN}_{3} \mathrm{O}_{2}$ : 409.0426).

\section{2-Amino-6-(2-benzyloxy-5-fluorophenyl)-4- (3, 4-dimethoxyphenyl) nicotinonitrile (3h)}

White power. mp: $170-171{ }^{\circ} \mathrm{C} .{ }^{1} \mathrm{H}$ NMR $(400 \mathrm{MHz}$, DMSO-d6, $\delta$ ppm): $7.68(\mathrm{~d}, \mathrm{~J}=9.1 \mathrm{~Hz}, 1 \mathrm{H}), 7.41-7.31$ (m, 8H), 7.15 (s, 1H, cyanopyridine), 6.97 (dd, $\mathrm{J}=31.7$, $13.3 \mathrm{~Hz}, 4 \mathrm{H}$ ), 5.17 (s, 2H, amidogen), 3.84 (s, 3H, methoxy), 3.73 (s, 3H, methoxy). ${ }^{13} \mathrm{C}$ NMR (100 MHz, DMSO-d6, $\delta$ ppm): 161.19, 156.27, 154.12, 150.42, $148.98,136.97,129.53,128.88,128.44,128.31,121.27$, $117.64,115.59,114.19,112.24,86.90,71.20,59.13$, 56.13, 56.03. IR (KBr) $\sigma / \mathrm{cm}^{-1}: 3470.41,3321.65$, 3184.79 , 2200.00, 1652.56, 1572.23, 1548.43, 1518.63, $1262.81,1140.83,1030.74,807.60,730.25,688.60$. HR ESI-MS (pos. ion mode): $\mathrm{m} / \mathrm{z}=456.1718[\mathrm{M}+\mathrm{H}]^{+}$(anal. calcd. for $\mathrm{C}_{27} \mathrm{H}_{22} \mathrm{FN}_{3} \mathrm{O}_{3}$ : 455.1645).

\section{2-Amino-6-(2, 4-bis (benzyloxy)phenyl)-4- (3,4-dimethoxyphenyl) nicotinonitrile (3i)}

Belge power. $159-160^{\circ} \mathrm{C} .{ }^{1} \mathrm{H}$ NMR (400 MHz, DMSOd6, $\delta$ ppm): $7.90(\mathrm{~d}, \mathrm{~J}=8.7 \mathrm{~Hz}, 1 \mathrm{H}), 7.51-7.47(\mathrm{~m}, 2 \mathrm{H})$, $7.42(\mathrm{t}, \mathrm{J}=7.4 \mathrm{~Hz}, 4 \mathrm{H}), 7.38-7.28(\mathrm{~m}, 5 \mathrm{H}), 7.13(\mathrm{~d}$, $\mathrm{J}=2.1 \mathrm{~Hz}, 1 \mathrm{H}), 6.98(\mathrm{~d}, \mathrm{~J}=8.4 \mathrm{~Hz}, 1 \mathrm{H}), 6.92(\mathrm{~d}, \mathrm{~J}=2.3$ $\mathrm{Hz}, 1 \mathrm{H}), 6.88-6.81(\mathrm{~m}, 1 \mathrm{H}), 6.81(\mathrm{~m}, 3 \mathrm{H}), 5.19(\mathrm{~d}$, $\mathrm{J}=2.9 \mathrm{~Hz}, 4 \mathrm{H}$, benzyloxy), 3.84 (s, 3H, methoxy), 3.72 (s, 3H, methoxy). ${ }^{13} \mathrm{C}$ NMR (100 MHz, DMSO-d6, $\delta$ ppm): 161.32, 161.12, 158.30, 157.49, 153.62, 150.26, $148.91,137.23,137.00,132.40,129.84,128.96,128.91$, $128.33,121.16,120.49,118.05,113.84,112.20,107.24$, $101.13,85.56,70.61,69.99,56.10,56.00$. IR (KBr) $\sigma /$ $\mathrm{cm}^{-1}: 3454.83,3361.04,2920.39,2206.18,1634.03$, $1603.86,1560.54,1514.22,1454.06,1364.47,1257.66$, 1777.78, 1132.43, 1022.66, 822.00, 729.31, 693.45.
HR-ESI-MS (pos. ion mode): $\mathrm{m} / \mathrm{z}=544.2241[\mathrm{M}$ $+\mathrm{H}]^{+}$(anal. calcd. for $\mathrm{C}_{34} \mathrm{H}_{29} \mathrm{~N}_{3} \mathrm{O}_{4}: 543.2158$ ).

\section{2-Amino-6-(2, 4-difluorophenyl)-4-(3,} 4-dimethoxyphenyl) nicotinonitrile (3j) White power. mp: $217-220^{\circ} \mathrm{C} .{ }^{1} \mathrm{H}$ NMR (400 MHz, DMSOd6, $\delta$ ppm): 7.99 (d, J =7.5 Hz, 1H), 7.39 (t, J=10.5 Hz, 2H), 7.25 (dd, J=18.3, $9.5 \mathrm{~Hz}, 3 \mathrm{H}), 7.08$ (d, J=42.4 Hz, 3H), 3.83 (s, 6H, methoxy). ${ }^{13} \mathrm{C}$ NMR (100 MHz, DMSO-d6, $\delta$ ppm): $201.21,185.06,161.35,150.60,149.14,139.96,135.86$, $132.99,129.36,121.47,119.46,112.36,112.30,112.27$, $100.45,90.45,56.11$. IR (KBr) $\sigma / \mathrm{cm}^{-1}: 3359.21,2924.70$, $2205.84,1625.63,1572.65,1544.24,1518.05,1267.17$, 1133.89, 1099.48, 1026.41，851.47, 791.36. HR-ESI-MS (pos. ion mode): $\mathrm{m} / \mathrm{z}=368.1217[\mathrm{M}+\mathrm{H}]^{+}$(anal. calcd. for $\mathrm{C}_{20} \mathrm{H}_{15} \mathrm{~F}_{2} \mathrm{~N}_{3} \mathrm{O}_{2}:$ : 367.1132).

\section{2-Amino-4-(2-bromophenyl)-6-(4-} bromophenyl) nicotinonitrile (3l)

Faint yellow power. mp: $162-164^{\circ} \mathrm{C} .{ }^{1} \mathrm{H}$ NMR $(400 \mathrm{MHz}$, DMSO-d6, $\delta \mathrm{ppm}): 8.07(\mathrm{~d}, \mathrm{~J}=7.6 \mathrm{~Hz}, 2 \mathrm{H}), 7.81(\mathrm{~d}$, $\mathrm{J}=7.2 \mathrm{~Hz}, 1 \mathrm{H}), 7.70(\mathrm{~s}, 2 \mathrm{H}), 7.50(\mathrm{~m}, 3 \mathrm{H}), 7.23(\mathrm{~s}, 1 \mathrm{H})$, 7.14 (s, 2H). ${ }^{13} \mathrm{C}$ NMR (100 MHz, DMSO-d6, $\delta$ ppm): $160.51,157.73,138.62,136.94,133.26,132.31,132.16$, $131.48,130.96,129.69,128.47,121.71,116.42,110.03$. IR (KBr) $\sigma / \mathrm{cm}^{-1}: 3483.25,3362.95,2214.86,1632.91$, $1572.02,1546.87,1446.52,1270.71,1007.51,824.79$, 754.01. HR-ESI-MS (pos. ion mode): $\mathrm{m} / \mathrm{z}=429.9376[\mathrm{M}$ $+\mathrm{H}]^{+}$(anal. calcd. for $\mathrm{C}_{18} \mathrm{H}_{11} \mathrm{Br}_{2} \mathrm{~N}_{3}$ : 428.9299).

\section{2-Amino-6-(2-(benzyloxy)-5- fluorophenyl)-4-(2-bromophenyl) nicotinonitrile $(3 \mathrm{~m})$}

Faint yellow power. mp: $146-148^{\circ} \mathrm{C} .{ }^{1} \mathrm{H}$ NMR $(400 \mathrm{MHz}$, DMSO-d6, $\delta$ ppm): 7.78 (d, J =7.2 Hz, 1H), 7.72 (d, J=9.6 $\mathrm{Hz}, 1 \mathrm{H}), 7.47$ (m, 2H), 7.30 (dd, J =16.6, 11.3 Hz, 9H), 7.09 (s, 2H), 5.15 (s, 2H, benzyloxy). ${ }^{13} \mathrm{C}$ NMR (100 MHz, DMSO-d6, $\delta$ ppm): 161.52, 160.31, 158.31, $157.64,153.74,138.87,137.18,136.96,133.18,132.48$, $131.18,130.69,128.96,128.76,128.37,127.72,121.69$, 120.17, 114.32, 107.38, 101.20. IR (KBr) $\sigma / \mathrm{cm}^{-1}$ : 3455.54, 3390.08, 3285.95, 2207.32, 1604.58, 1569.80, 1546.78, 1266.52, 1180.84, 1024.69, 731.73. HR-ESI-MS (pos. ion mode): $\mathrm{m} / \mathrm{z}=476.0593[\mathrm{M}+\mathrm{H}]^{+}$(anal. calcd. for $\mathrm{C}_{25} \mathrm{H}_{17} \mathrm{BrFN}_{3} \mathrm{O}: 475.0519$ (97.3\%)). 
2-Amino-6-(2, 4-bis (benzyloxy) Phenyl)4-(2-bromophenyl) nicotinonitrile $(3 n)$

White power. mp: $171-173^{\circ} \mathrm{C} .{ }^{1} \mathrm{H}$ NMR $(400 \mathrm{MHz}$, DMSO-d6, $\delta$ ppm): 7.93(d, J=8.7 Hz, 1H), 7.77 (s, 1H), $7.41(\mathrm{~m}, 9 \mathrm{H}), 7.23(\mathrm{~d}, \mathrm{~J}=17.5 \mathrm{~Hz}, 5 \mathrm{H}), 6.93$ (s, 3H), $6.80(\mathrm{~d}, \mathrm{~J}=7.3 \mathrm{~Hz}, 1 \mathrm{H}), 5.18(\mathrm{~d}, \mathrm{~J}=11.1 \mathrm{~Hz}, 4 \mathrm{H}$, benzyloxy), $4.35(\mathrm{~d}, \mathrm{~J}=3.2 \mathrm{~Hz}, 2 \mathrm{H}) .{ }^{13} \mathrm{C}$ NMR $(100$ $\mathrm{MHz}$, DMSO-d6, $\delta$ ppm): 160.35, 158.05, 156.39, $155.70,154.23, \quad 153.40, \quad 138.57,136.89,133.23$, $131.34, \quad 130.69, \quad 128.76, \quad 128.42, \quad 128.23, \quad 127.82$, $121.63,117.94,117.71,117.28,117.04,116.41,115.75$, 115.67, 114.71, 88.91,71.09. IR (KBr) $\sigma / \mathrm{cm}^{-1}: 3490.49$, 3363.26, 2218.47, 1623.93, 1569.13, 1599.12, 1420.92, 1261.12, 1205.33, 1025.16, 780.48, 763.31, 753.71. HRESI-MS (pos. ion mode): $\mathrm{m} / \mathrm{z}=564.1107[\mathrm{M}+\mathrm{H}]^{+}$(calcd. for $\mathrm{C}_{32} \mathrm{H}_{24} \mathrm{BrN}_{3} \mathrm{O}_{2}$ : $563.1031(97.3 \%)$ ).

\section{General Procedure For The Compounds 4a-4o (Scheme 2)}

A mixture of the substituted acetophenone $(1 \mathrm{mmol})$, together with the respective benzaldehyde $(1 \mathrm{mmol})$, ethylcyanoacetate $(1 \mathrm{mmol})$ and ammonium acetate (8mmol) in toluene $(10 \mathrm{~mL})$ was stirred at reflux for 8 $12 \mathrm{hrs}$. After cooling to room temperature, the mixture was diluted ethyl acetate and THF. The organic phase was washed twice with brine, dried over $\mathrm{Na}_{2} \mathrm{SO}_{4}$, the filtrate and concentrated under reduced pressure. The residue was suspended in absolute ethanol. The precipitate was collected by filtration and purified by silica gel column chromatography to give the desired product.

\section{4, 6-bis(4-bromophenyl)-2-oxo-1,2- dihydropyridine-3-carbonitrile (4a)}

Yellow power. mp: $168-170^{\circ} \mathrm{C} .{ }^{1} \mathrm{H}$ NMR $(400 \mathrm{MHz}$, DMSO-d6, $\delta \mathrm{ppm}): 10.44(\mathrm{~s}, 1 \mathrm{H}), 8.08(\mathrm{~d}, \mathrm{~J}=8.0 \mathrm{~Hz}$, 2H), $7.84(\mathrm{~d}, \mathrm{~J}=7.4 \mathrm{~Hz}, 2 \mathrm{H}), 7.66(\mathrm{~s}, 3 \mathrm{H}), 6.90$ (d, J=8.0 $\mathrm{Hz}, 2 \mathrm{H}) .{ }^{13} \mathrm{C}$ NMR (400 MHz, DMSO-d6, $\delta$ ppm): 187.47, $162.77,141.80,134.69,132.30,131.73,131.10,129.48$, 124.09, 123.41, 115.87. IR (KBr) $\sigma / \mathrm{cm}^{-1}: 3215.87$, 2368.47, 1654.30, 1598.86, 1573.37, 1513.99, 1486.06, 1334.97, 1279.95, 1225.22, 1167.92, 812.66. HR-ESI-MS (pos. ion mode): $\mathrm{m} / \mathrm{z}=367.0077[\mathrm{M}+\mathrm{H}]^{+}$(anal. calcd. for $\mathrm{C}_{18} \mathrm{H}_{11} \mathrm{BrN}_{2} \mathrm{O}_{2}$ : 366.0004).

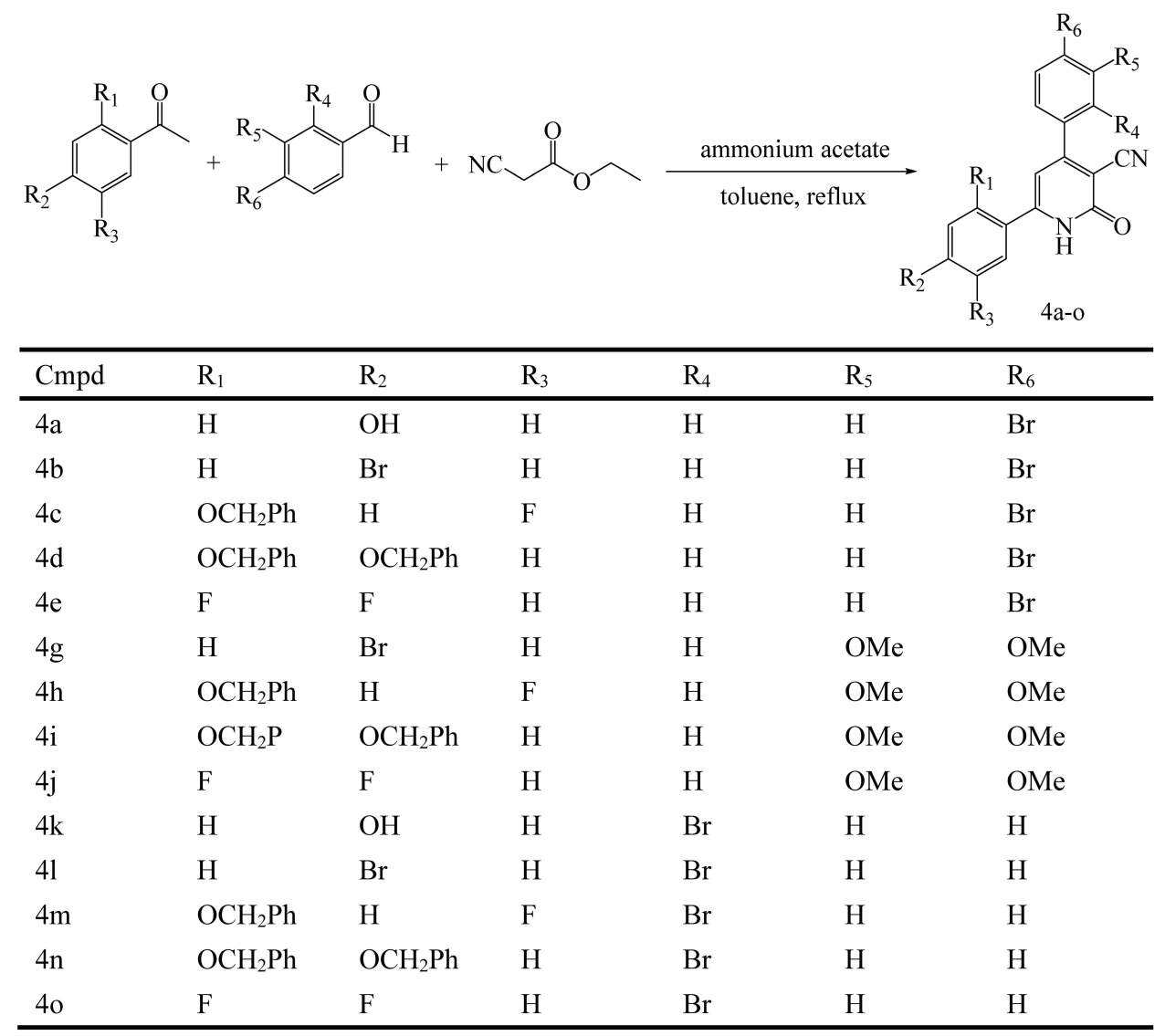

Scheme 2 The design route of 2-oxo-cyanopyridines and the chemical structure of the compound 4a-o. 


\section{4-(4-bromophenyl)-6-(4-hydroxyphenyl)-2-} oxo-I, 2-dihydropyridine-3-carbonitrile (4b) Faint yellow power. mp: $325-327^{\circ} \mathrm{C}$. ${ }^{1} \mathrm{H}$ NMR $(400 \mathrm{MHz}$, DMSO-d6, $\delta$ ppm): 12.94 (s, 1H, lactam), 7.77 (m, 8H, aromatic), 6.91 (s, $1 \mathrm{H}$, cyanopyridine). ${ }^{13} \mathrm{C}$ NMR $(100$ MHz, DMSO-d6, $\delta \mathrm{ppm}): 135.53,132.34,132.27$, $130.92,130.32,125.48,124.63,116.72$. IR (KBr) $\sigma /$ $\mathrm{cm}^{-1}: 3074.36,2926.19,2218.79,1631.61,1602.66$, $1560.68,1493.18,1349.03,1233.38,1066.77,1006.65$, 816.63, 556.73, 494.32. HR-ESI-MS (pos. ion mode): $\mathrm{m} /$ $\mathrm{z}=430.9213[\mathrm{M}+\mathrm{H}]^{+}$(calcd. for $\mathrm{C}_{18} \mathrm{H}_{10} \mathrm{Br}_{2} \mathrm{~N}_{2} \mathrm{O}: 429.9139$ ).

\section{6-(2-(benzyloxy)-5-fluorophenyl)-4-(4- bromophenyl)-2-oxo-I,2- dihydropyridine-3-carbonitrile (4c)}

Yellow needle power. mp: $118-120^{\circ} \mathrm{C} .{ }^{1} \mathrm{H}$ NMR $(400$ MHz, DMSO-d6, $\delta$ ppm): $7.71(\mathrm{~m}, 1 \mathrm{H}), 7.54$ (d, J =8.5 $\mathrm{Hz}, 3 \mathrm{H}), 7.33$ (m, 8H), 7.21 (s, 1H), 6.99 (d, J=8.4 Hz, $2 \mathrm{H}), 6.73$ (s, $2 \mathrm{H}), 5.14(\mathrm{~s}, 2 \mathrm{H}) \cdot{ }^{13} \mathrm{C}$ NMR $(400 \mathrm{MHz}$, DMSO-d6, $\delta$ ppm): 167.81, 166.22, 158.44, 154.72, $153.41,150.78,140.19,136.03,131.87,131.51,129.89$, 128.90, 128.57, 121.60, 117.34, 116.91, 115.59, 106.06, 71.22. IR (KBr) $\sigma / \mathrm{cm}^{-1}: 3415.51,3272.92,3173.49$, $2985.27,2247.60,1680.28,1615.98,1572.50,1491.94$, $1282.43,1250.94,1192.61,1108.16,1011.47,810.47$, 735.28. HR-ESI-MS (pos. ion mode): $\mathrm{m} / \mathrm{z}=475.0450[\mathrm{M}$ $+\mathrm{H}]^{+}$(calcd. for $\mathrm{C}_{25} \mathrm{H}_{16} \mathrm{BrFN}_{2} \mathrm{O}_{2}: 474.0379$ ).

\section{6-(2, 4-bis (benzyloxy)phenyl)-4-(4- bromophenyl)-2-oxo-I,2- dihydropyridine-3-carbonitrile (4d)}

Faint yellow power. mp: $165-168^{\circ} \mathrm{C} .{ }^{1} \mathrm{H}$ NMR $(400 \mathrm{MHz}$, DMSO-d6, $\delta$ ppm): 7.91 (d, J=8.7 Hz, 1H), $7.41(\mathrm{~m}, 13 \mathrm{H})$, $7.13(\mathrm{~s}, 1 \mathrm{H}), 6.97$ (d, J=8.3 Hz, 2H), 6.70 (s, 2H), 5.17 (d, $\mathrm{J}=20.0 \mathrm{~Hz}, 4 \mathrm{H}$, benzyloxy). ${ }^{13} \mathrm{C}$ NMR (100 MHz, DMSO$\mathrm{d} 6, \delta \mathrm{ppm}): 167.98,161.14,158.59,158.25,150.78$, $140.69,137.27,136.94,132.24,131.40,129.87,128.95$, $128.92,128.58,128.44,128.34,121.35,115.38,107.15$, $100.98,70.64,69.98$. IR (KBr) $\sigma / \mathrm{cm}^{-1}: 3422.83,3266.96$, 3168.02, 2918.61, 2360.65, 1680.43, 1603.46, 1571.60, $1488.09,1258.68,1186.16,1100.30,1021.82,1011.92$, 818.95, 735.55, 693.30. HR-ESI-MS (pos. ion mode): $\mathrm{m} /$ $\mathrm{z}=563.0972[\mathrm{M}+\mathrm{H}]^{+}$(calcd. for $\mathrm{C}_{32} \mathrm{H}_{23} \mathrm{BrN}_{2} \mathrm{O}_{3}:$ 562.0892).

\section{4-(4-bromophenyl)-6-(2, 4-} difluorophenyl)-2-oxo-I, 2dihydropyridine-3-carbonitrile (4e)

Brown power. mp: $258-260^{\circ} \mathrm{C} .{ }^{1} \mathrm{H}$ NMR $(400 \mathrm{MHz}$, DMSO-d6, $\delta$ ppm): 12.95 (s, 1H), $7.78(\mathrm{~m}, 7 \mathrm{H}), 6.87$ (s, 1H). ${ }^{13} \mathrm{C}$ NMR (100 MHz, DMSO-d6, $\delta$ ppm): 161.23, $160.10,159.25,153.75,136.84,132.14,130.94,129.47$, 128.70, 123.54, 117.62, 115.88, 108.48, 85.45. IR (KBr) б/ $\mathrm{cm}^{-1}: 3457.31,3350.13,2206.09,1620.56,1574.89$, 1544.68, 1491.87, 1456.89, 1363.84, 1231.59, 1172.57, 805.77. HR-ESI-MS (pos. ion mode): $\mathrm{m} / \mathrm{z}=386.9782[\mathrm{M}$ $+\mathrm{H}]^{+}$(calcd. for $\mathrm{C}_{18} \mathrm{H}_{9} \mathrm{BrF}_{2} \mathrm{~N}_{2} \mathrm{O}: 385.9866$ ).

\section{6-(4-bromophenyl)-4-(3, 4- dimethoxyphenyl)-2-oxo-I, 2- dihydropyridine-3-carbonitrile (4g)}

Faint yellow power. mp: $309-312^{\circ} \mathrm{C} .{ }^{1} \mathrm{H}$ NMR (400 MHz, DMSO-d6, $\delta$ ppm): $12.75(\mathrm{~s}, 1 \mathrm{H}), 7.80(\mathrm{~d}, \mathrm{~J}$ $=36.8 \mathrm{~Hz}, 4 \mathrm{H}), 7.36(\mathrm{~d}, \mathrm{~J}=8.9 \mathrm{~Hz}, 2 \mathrm{H}), 7.14$ (d, J=8.1 $\mathrm{Hz}, 1 \mathrm{H}), 6.89$ (s, 1H), 3.85 (s, 6H). ${ }^{13} \mathrm{C}$ NMR $(100$ $\mathrm{MHz}$, DMSO-d6, $\delta$ ppm): 151.27, 149.08, 132.31, $130.30,128.45,15.29,125.26,122.01,112.41,112.09$, 56.20, 56.18. IR (KBr) $\sigma / \mathrm{cm}^{-1}: 2933.95,2838.96$, 2220.79, 1632.59, 1598.04, 1515.67, 1494.22, 1421.33, $1261.98,1217.85,1148.23,1021.81,831.19$. HR-ESIMS (pos. ion mode): $\mathrm{m} / \mathrm{z}=411.0172[\mathrm{M}+\mathrm{H}]^{+}$(calcd. for $\mathrm{C}_{20} \mathrm{H}_{15} \mathrm{BrN}_{2} \mathrm{O}_{3}: 410.0266$ ).

\section{6-(2-(benzyloxy)-5-fluorophenyl)-4-(3,4- dimethoxyphenyl)-2-oxo-I,2- dihydropyridine-3-carbonitrile (4h)}

Faint yellow power. mp: $205-208^{\circ} \mathrm{C} .{ }^{1} \mathrm{H}$ NMR (400 MHz, DMSO-d6, $\delta$ ppm): 12.57 (s, 1H), 7.52-7.22 (m, $\mathrm{J}=30.3 \mathrm{~Hz}, 10 \mathrm{H}), 7.10(\mathrm{~d}, \mathrm{~J}=7.7 \mathrm{~Hz}, 1 \mathrm{H}), 6.67(\mathrm{~s}, 1 \mathrm{H})$, $5.16(\mathrm{~s}, 2 \mathrm{H}), 3.84(\mathrm{~s}, 3 \mathrm{H}), 3.79$ (s,3H). ${ }^{13} \mathrm{C}$ NMR (100 MHz, DMSO-d6, $\delta$ ppm): 154.24, 149.04, 136.92, $128.90,128.86,128.57,128.42,128.11,128.08$, $121.83,115.35,112.29,112.28,112.08,82.75,71.03$, 71.02, 58.30, 56.16, 56.12. IR (KBr) $\sigma / \mathrm{cm} 1: 3420.98$, 2 927.97, 2838.63, 2221.89, 1654.48, 1603.88, 1518.79, 1262.70, 1146.03, 1032.76, 818.53, 730.35. HR-ESI-MS (pos. ion mode): $\mathrm{m} / \mathrm{z}=455.1418[\mathrm{M}-\mathrm{H}]^{+}$(calcd. for $\mathrm{C}_{27} \mathrm{H}_{21} \mathrm{FN}_{2} \mathrm{O}_{4}$ : 456.1485). 
6-(2,4-bis(benzyloxy)phenyl)-4-(3,4dimethoxyphenyl)-2-oxo-I,2-

dihydropyridine-3-carbonitrile (4i)

Faint yellow power. mp: $178-180^{\circ} \mathrm{C} .{ }^{1} \mathrm{H} \mathrm{NMR}(400 \mathrm{MHz}$, DMSO-d6, $\delta$ ppm): 7.87 (d, J=7.8 Hz, 1H), 7.48-7.33 (m, $10 \mathrm{H}), 7.20(\mathrm{~s}, 1 \mathrm{H}), 6.90(\mathrm{~s}, 2 \mathrm{H}), 6.78-6.73(\mathrm{~m}, 2 \mathrm{H}), 6.57$ $(\mathrm{d}, \mathrm{J}=6.0 \mathrm{~Hz}, 1 \mathrm{H}), 6.49$ (s, 1H), $5.18(\mathrm{~s}, 4 \mathrm{H}), 3.80(\mathrm{~s}, 3 \mathrm{H})$, 3.66 (s, 3H). ${ }^{13} \mathrm{C}$ NMR (400 MHz, DMSO-d6, $\delta$ ppm): $168.65,160.85,158.13,158.03,155.71,148.77,137.11$, $133.64,128.95,128.87,128.41,128.32,128.24,124.80$, $124.74,120.18,112.11,101.11,70.51,69.95$. IR (KBr) $\sigma /$ $\mathrm{cm}^{-1}: 3427.79,2961.41,2922.03,2360.35,1679.82$, 1603.49 , 1562.38, 1508.49, 1457.52, 1260.44, 1104.97, 1025.11, 815.30. HR-ESI-MS (pos. ion mode): m/ $\mathrm{z}=545.2073[\mathrm{M}+\mathrm{H}]^{+}$(calcd. for $\mathrm{C}_{34} \mathrm{H}_{28} \mathrm{~N}_{2} \mathrm{O}_{5}$ : 544.1998).

\section{6-(2, 4-difluorophenyl)-4-(3, 4-} dimethoxyphenyl)-2-oxo- I, 2dihydropyridine-3-carbonitrile (4j)

Yellow power. mp: $253-255^{\circ} \mathrm{C} .{ }^{1} \mathrm{H}$ NMR $(400 \mathrm{MHz}$, DMSO-d6, $\delta$ ppm): 7.85 (s, 1H), 7.42 (t, J=12.5 Hz, 1H), 7.25 (s, 3H), $7.11(\mathrm{~s}, 1 \mathrm{H}), 6.65$ (d, J=29.9 Hz, 1H), 5.31 (s, 1H), 3.83 (s, 6H), 3.82 (s, 6H). ${ }^{13} \mathrm{C}$ NMR (100MHz, DMSOd6, $\delta$ ppm): 150.73, 148.98, 133.00, 132.99, 132.93, 132.89, $121.58,112.52,112.30,112.25,112.09,105.11$. IR (KBr) $\sigma /$ $\mathrm{cm}^{-1}: \quad 3444.10,3055.13,2919.16,2847.54,2360.58$, 2215.93, 1656.98, 1617.30, 1520.05, 1271.72, 1023.85, 801.99. HR-ESI-MS (pos. ion mode): $\mathrm{m} / \mathrm{z}=369.1045$ [M$2 \mathrm{H}]^{+}$(calcd. for $\mathrm{C}_{20} \mathrm{H}_{15} \mathrm{~F}_{2} \mathrm{~N}_{3} \mathrm{O}_{2}: 367.1132$ ).

\section{4-(2-bromophenyl)-6-(4-hydroxyphenyl)- 2-oxo-I, 2-dihydropyridine-3-carbonitrile $(4 k)$}

Brown power. mp: $132-135^{\circ} \mathrm{C} .{ }^{1} \mathrm{H}$ NMR $(400 \mathrm{MHz}$, DMSO-d6, $\delta \mathrm{ppm}): 9.88(\mathrm{~s}, 1 \mathrm{H}), 7.98(\mathrm{t}, 1 \mathrm{H}), 7.95(\mathrm{t}$, 1H), 7.67-7.55 (m, 1H), 7.46-7.41 (td, J=7.5, 1.2 Hz, 1H), 7.34-7.29 (m, 2H), $7.13(\mathrm{~s}, 2 \mathrm{H}), 6.84(\mathrm{~s}, 2 \mathrm{H}), 6.82(\mathrm{~d}$, $\mathrm{J}=1.9 \mathrm{~Hz}, 1 \mathrm{H}) .{ }^{13} \mathrm{C}$ NMR $(100 \mathrm{MHz}, \mathrm{DMSO}-\mathrm{d} 6, \delta \mathrm{ppm})$ : $159.83,158.23,152.96,143.30,132.26,131.17,129.83$, $129.45,129.15,128.79,127.80,121.70,115.86,110.41$, 103.37. IR (KBr) $\sigma / \mathrm{cm}^{-1}: 3470.22,3413.54,3369.47$, $1686.21,1599.93,1570.73,1516.70,1360.58,1282.87$, 1230.64, 1169.10, 1102.44, 823.99, 755.09. HR-ESI-MS (pos. ion mode): $\mathrm{m} / \mathrm{z}=367.0089[\mathrm{M}+\mathrm{H}]^{+}$(calcd. for $\mathrm{C}_{18} \mathrm{H}_{11} \mathrm{BrN}_{2} \mathrm{O}_{2}$ : 366.0004).

\section{4-(2-bromophenyl)-6-(4-bromophenyl)-2-} oxo-I, 2-dihydropyridine-3-carbonitrile (4I) Faint yellow cottony. mp: $298-300^{\circ} \mathrm{C} .{ }^{1} \mathrm{H}$ NMR $(400$ MHz, DMSO-d6, $\delta$ ppm): 13.00 (s, 1H), 7.79 (d, J=37.2 $\mathrm{Hz}, 4 \mathrm{H}), 7.51(\mathrm{~d}, \mathrm{~J}=27.3 \mathrm{~Hz}, 3 \mathrm{H}), 6.81(\mathrm{~s}, 1 \mathrm{H}) .{ }^{13} \mathrm{C}$ NMR (100 MHz, DMSO-d6, $\delta$ ppm): 137.74, 133.41, 132.41, $131.91,130.52,130.25,128.58$. IR $(\mathrm{KBr}) \sigma / \mathrm{cm}^{-1}$ : 3443.64, 2923.41, 2222.70, 1644.73, 1605.78, 1561.63, 1493.79, 1229.05, 1009.22, 823.69, 751.75. HR-ESI-MS (pos. ion mode): $\mathrm{m} / \mathrm{z}=430.9051[\mathrm{M}+\mathrm{H}]^{+}$(calcd. for $\left.\mathrm{C}_{18} \mathrm{H}_{10} \mathrm{Br}_{2} \mathrm{~N}_{2} \mathrm{O}: 429.9139\right)$.

\section{6-(2-(benzyloxy)-5-fluorophenyl)-4-(2- bromophenyl)-2-oxo-I,2- dihydropyridine-3-carbonitrile $(4 \mathrm{~m})$}

Faint yellow power. mp: $167-169^{\circ} \mathrm{C} .{ }^{1} \mathrm{H}$ NMR $(400 \mathrm{MHz}$, DMSO-d6, $\delta$ ppm): $7.96(\mathrm{~d}, \mathrm{~J}=8.7 \mathrm{~Hz}, 1 \mathrm{H}), 7.64$ (dd, $\mathrm{J}=7.9,1.2 \mathrm{~Hz}, 1 \mathrm{H}), 7.50(\mathrm{~m}, 2 \mathrm{H}), 7.42(\mathrm{~m}, 2 \mathrm{H}), 7.33(\mathrm{~m}$, $3 \mathrm{H}), 7.08(\mathrm{~m}, 3 \mathrm{H}), 6.92(\mathrm{~d}, \mathrm{~J}=2.3 \mathrm{~Hz}, 1 \mathrm{H}), 6.80(\mathrm{dd}, \mathrm{J}=8.7$, $2.3 \mathrm{~Hz}, 1 \mathrm{H}), 5.19$ (d, J=5.0 Hz, 2H). ${ }^{13} \mathrm{C}$ NMR $(100 \mathrm{MHz}$, DMSO-d6, $\delta$ ppm): 161.26, 159.52, 158.26, 156.99, $151.91,143.25,137.23,128.95,128.77,128.37,128.37$, $127.70,121.64,120.36,115.88,107.23,103.34,101.12$. 70.44. IR (KBr) $\sigma / \mathrm{cm}^{-1}$ : 3424.16, 3263.82, 3164.77, 2924.13, 2357.69, 1677.35, 1603.39, 1569.37, 1261.04, 1186.93, 1109.95, 1025.89, 817.52, 733.30, 693.96. HRESI-MS (pos. ion mode): $\mathrm{m} / \mathrm{z}=475.0450[\mathrm{M}+\mathrm{H}]^{+}$(calcd. for $\mathrm{C}_{25} \mathrm{H}_{16} \mathrm{BrFN}_{2} \mathrm{O}_{2}$ : 474.0379).

\section{6-(2, 4-bis (benzyloxy) Phenyl)-4-(2- bromophenyl)-2-oxo- I, 2- dihydropyridine-3-carbonitrile $(4 n)$}

White power. mp: $170-172^{\circ} \mathrm{C} .{ }^{1} \mathrm{H}$ NMR $(400 \mathrm{MHz}$, DMSO-d6, $\delta \mathrm{ppm}): 7.95(\mathrm{~d}, \mathrm{~J}=8.3 \mathrm{~Hz}, 1 \mathrm{H}), 7.64(\mathrm{~d}$, $\mathrm{J}=6.3 \mathrm{~Hz}, 1 \mathrm{H}), 7.38(\mathrm{dd}, \mathrm{J}=61.3,24.8 \mathrm{~Hz}, 12 \mathrm{H}), 7.07$ (s, 4H), $6.91(\mathrm{~s}, 1 \mathrm{H}), 6.80(\mathrm{~d}, \mathrm{~J}=7.9 \mathrm{~Hz}, 1 \mathrm{H}), 5.17(\mathrm{~d}$, $\mathrm{J}=19.3 \mathrm{~Hz}, 4 \mathrm{H}) .{ }^{13} \mathrm{C}$ NMR (100 MHz, DMSO-d6, $\delta$ ppm): 159.39, 152.13, 142.80, 136.91, 132.26, 129.58, $129.48,128.90,128.77,128.20,127.81,121.56,117.56$, $117.34,117.23,116.98,116.20,115.65,115.57,104.85$. IR $(\mathrm{KBr}) \sigma / \mathrm{cm}^{-1}: 3422.71,3263.89,3165.39,2922.32$, 2337.22, 1617.43, 1602.93, 1568.64, 1259.88, 1185.94, 1107.73, 1024.55, 817.10, 732.12, 693.23.HR-ESI-MS (pos. ion mode): $\mathrm{m} / \mathrm{z}=563.0972[\mathrm{M}+\mathrm{H}]^{+}$(calcd. for $\mathrm{C}_{32} \mathrm{H}_{23} \mathrm{BrN}_{2} \mathrm{O}_{3}:$ 562.0892). 
4-(2-bromophenyl)-6-(2, 4difluorophenyl)-2-oxo- I, 2dihydropyridine-3-carbonitrile (4o)

White power. mp: $300-302{ }^{\circ} \mathrm{C} .{ }^{1} \mathrm{H}$ NMR $(400 \mathrm{MHz}$, DMSO-d6, $\delta$ ppm): 13.09 (s, 1H), 7.80 (d, J=15.4 Hz, 2H), 7.55-7.47 (m, 4H), $7.28(\mathrm{~s}, 1 \mathrm{H}), 6.61(\mathrm{~s}, 1 \mathrm{H}) .{ }^{13} \mathrm{C}$ NMR (100 MHz, DMSO-d6, $\delta$ ppm): 137.52, 133.47, $133.06,132.96,132.01,130.47,128.62,120.87,115.63$, $112.95,105.77,105.50,105.24$. IR $(\mathrm{KBr}) \sigma / \mathrm{cm}^{-1}$ : 3443.52 , 2778.95, 2221.46, 1650.66, 1614.21, 1506.77, $1269.52,1226.79,1110.34,949.56,853.61,756.74$. HRESI-MS (pos. ion mode): $\mathrm{m} / \mathrm{z}=386.9782[\mathrm{M}+\mathrm{H}]^{+}$(calcd. for $\mathrm{C}_{18} \mathrm{H}_{9} \mathrm{BrF}_{2} \mathrm{~N}_{2} \mathrm{O}: 385.9866$ ).

\section{Screening Of Cyanopyridines Against}

\section{Human Cancer Cells In Vitro}

First, all the synthesized cyanopyridines were evaluated for their antiproliferative activity against a variety of cancer cells by the MTT assay in vitro (Tables 1-2). Among the cyanopyridines $\mathbf{3 n}$ exhibited potent inhibitory activity on all HCT-116, Hela, and A375 cells with the IC50 values of $10.50,14.27$ and $4.61 \mu \mathrm{M}$, respectively, which was the more potent compound for further study.

From the preliminary structure-activity relationships, we may conclude that introduction of benzyloxy group to the 1-position and 2-position of phenyl ring slightly enhance the cytotoxic activity, meanwhile bromine substituent to the 6-position on phenyl ring even had decreased

Table I IC50 of 3a-n for HCT-I I6, Hela229, and A375 (IC50 in $\mu \mathrm{M})$

\begin{tabular}{|l|l|l|l|}
\hline Comp. & \multirow{2}{*}{ HCT-I I6 } & Cell line & \multirow{2}{*}{ A375 } \\
Code & & Hela229 & \\
\hline $3 \mathrm{a}$ & $>40$ & $>40$ & $>40$ \\
$3 \mathrm{~b}$ & $0.22 \pm 0.12$ & $26.85 \pm 0.9 \mathrm{I}$ & $>40$ \\
$3 \mathrm{c}$ & $>40$ & $33.53 \pm 1.20$ & $>40$ \\
$3 \mathrm{~d}$ & $>40$ & $>40$ & $>40$ \\
$3 \mathrm{e}$ & $2.18 \pm 0.32$ & $21.69 \pm 1.15$ & $12.69 \pm 1.01$ \\
$3 \mathrm{f}$ & $>40$ & $5.80 \pm 0.94$ & $30.17 \pm 1.30$ \\
$3 \mathrm{~g}$ & $35.51 \pm 0.85$ & $5.22 \pm 0.65$ & $6.49 \pm 0.78$ \\
$3 \mathrm{~h}$ & $>40$ & $17.46 \pm 1.05$ & $9.41 \pm 0.46$ \\
$3 \mathrm{i}$ & $4.74 \pm 0.5 \mathrm{I}$ & $6.63 \pm 0.84$ & $24.97 \pm 1.20$ \\
$3 \mathrm{j}$ & $8.16 \pm 0.63$ & $32.47 \pm 0.74$ & $37.58 \pm 1.32$ \\
$3 \mathrm{I}$ & $6.07 \pm 0.56$ & $>40$ & $19.54 \pm 1.10$ \\
$3 \mathrm{~m}$ & $>40$ & $>40$ & $>40$ \\
$3 \mathrm{n}$ & $10.50 \pm 1.01$ & $14.27 \pm 1.00$ & $4.61 \pm 0.75$ \\
\hline
\end{tabular}

Abbreviation: IC50, 50\% inhibiting concentration.
Table 2 IC50 of 4a-o for HCT-I I6, Hela229, and A375 (IC50 in $\mu \mathrm{M})$

\begin{tabular}{|c|c|c|c|}
\hline Comp. & \multirow[t]{2}{*}{ НCT-I I 6} & Cell line & \multirow[t]{2}{*}{ A375 } \\
\hline Code & & Hela229 & \\
\hline $4 a$ & $35.56 \pm 0.65$ & $12.40 \pm 0.68$ & $22.17 \pm 0.67$ \\
\hline $4 b$ & $20.17 \pm 1.30$ & $8.08 \pm 0.74$ & $8.08 \pm 0.56$ \\
\hline $4 c$ & $>40$ & $17.53 \pm 1.10$ & $19.93 \pm 1.00$ \\
\hline $4 d$ & $>40$ & $29.26 \pm 1.03$ & $>40$ \\
\hline $4 e$ & $1.67 \pm 0.56$ & $6.75 \pm 0.75$ & $>40$ \\
\hline $4 g$ & $37.81 \pm 0.65$ & $>40$ & $>40$ \\
\hline $4 \mathrm{~h}$ & $10.10 \pm 0.56$ & $2.48 \pm 0.64$ & $>40$ \\
\hline $4 i$ & $>40$ & $>40$ & $20.88 \pm 0.65$ \\
\hline $4 j$ & $>40$ & $8.21 \pm 0.53$ & $33.04 \pm 0.74$ \\
\hline $4 k$ & $7.5 I \pm 0.69$ & $5.00 \pm 0.91$ & $\mid 6.79 \pm 1.01$ \\
\hline 41 & $34.86 \pm 1.20$ & $31.91 \pm 1.04$ & $|5.2| \pm 0.72$ \\
\hline $4 m$ & $>40$ & $>40$ & $>40$ \\
\hline $4 n$ & $16.93 \pm 1.01$ & $>40$ & $>40$ \\
\hline 40 & $>40$ & $17.91 \pm 1.20$ & $16.19 \pm 0.85$ \\
\hline
\end{tabular}

activity compared to $3 n$. Furthermore, the compound $3 n$ with 2-amino substituent was more active than 2-oxo congener $4 n$.

\section{Active Compounds 3n Inhibited Migration And Colony Formation Of Colorectal Cancer Cells}

Moreover, DLD-1 and RKO cells were treated with different concentrations of $\mathbf{3 n}$ to evaluate the effect of 3n on colorectal cancer cells migration (Figure 1A). The migration ability of cells treated with $\mathbf{3 n}$ was significantly reduced, which highlighted the critical role of $\mathbf{3 n}$ in inhibition of colorectal cancer cell migration. In addition, to observe the effect of $\mathbf{3 n}$ on the proliferation of colorectal cancer cells, we performed colony formation assays. Similar effects were observed in colony formation assays, $\mathbf{3 n}$ remarkably reduced the colony formation capacity in HCT116, RKO, and DLD-1 cancer cell lines (Figure 1B).

\section{The Compounds 3n Inhibited The Phosphorylation Of STAT3}

Aminocyanopyridines can inhibit cell proliferation and induce cell death in human cancer cells by inhibiting the STAT3 pathway. ${ }^{17}$ We next validated the effects of $\mathbf{3 n}$ on STAT3 signaling in three colorectal cancer cells. As shown in Figure 2A, STAT3 phosphorylation was inhibited in a time-dependent manner with a $40 \mu \mathrm{M}$ concentration of $3 \mathrm{n}$, which significantly inhibited STAT3 phosphorylation at 24 
A
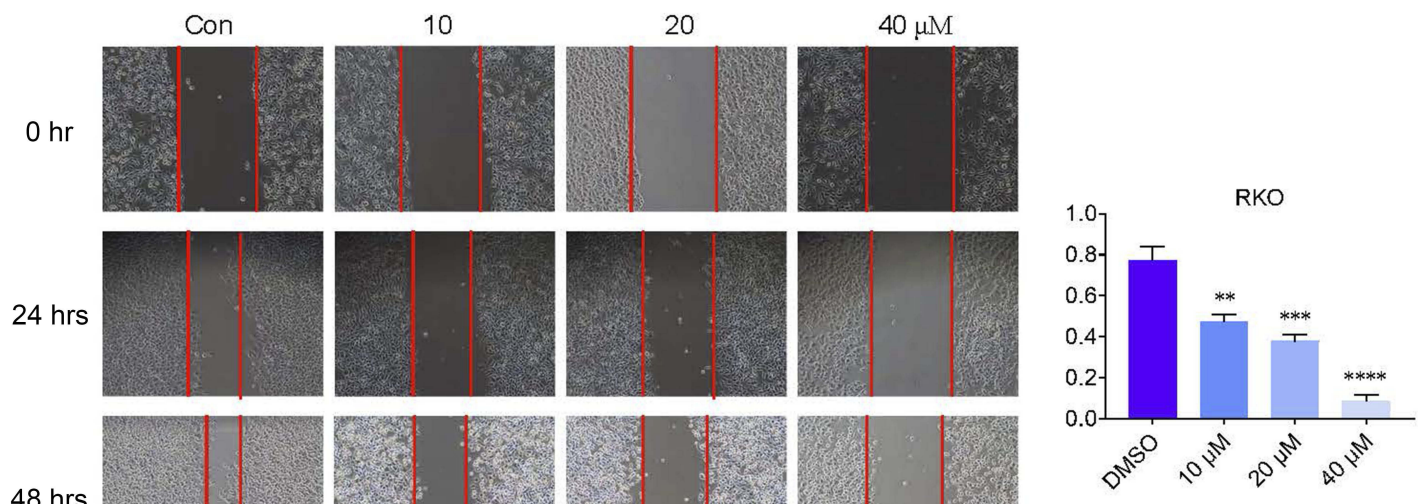

$48 \mathrm{hrs}$
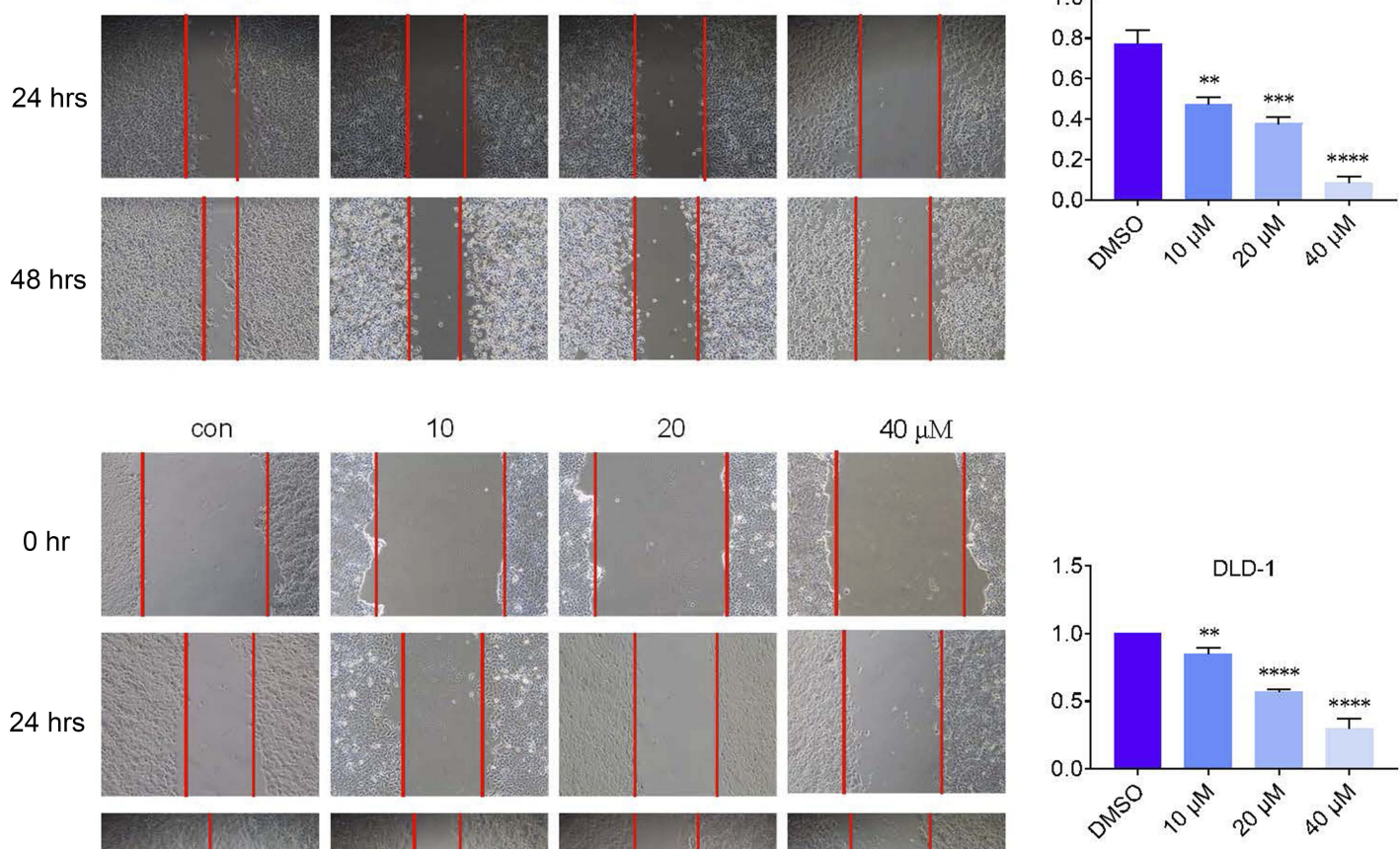

$48 \mathrm{hrs}$
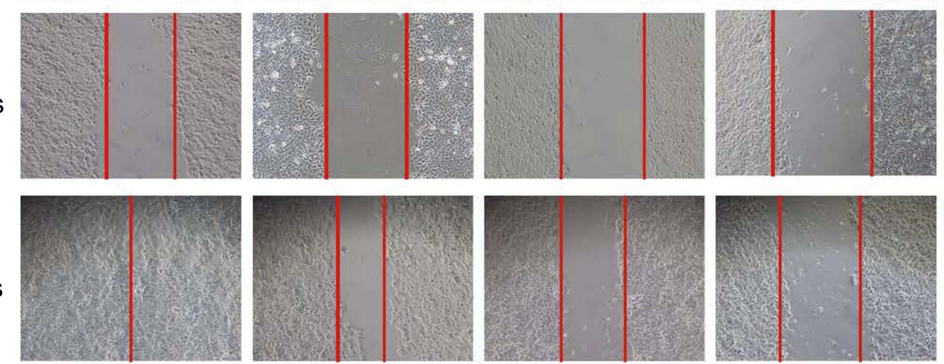

B
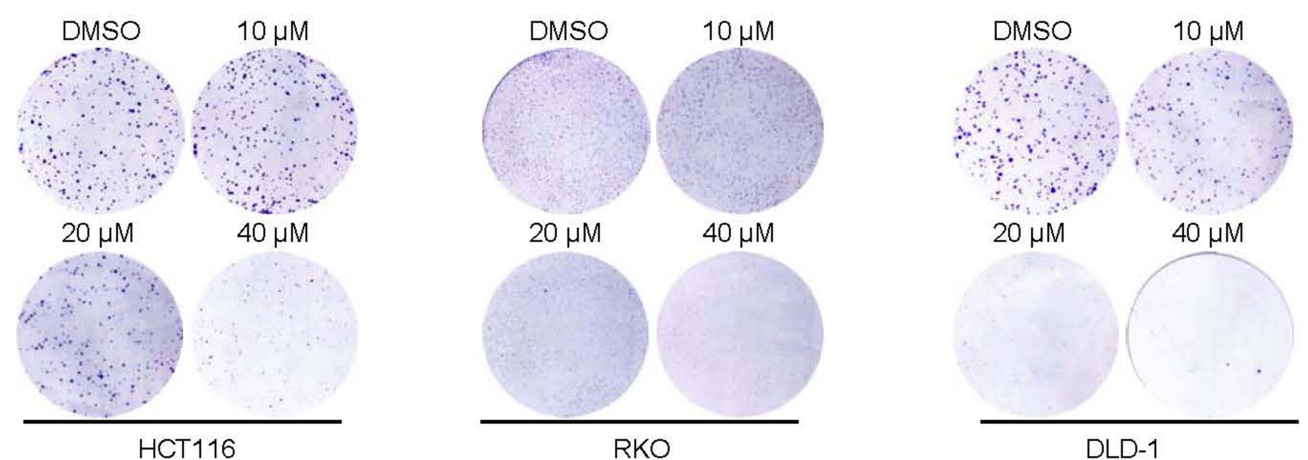

Figure I The compound $3 \mathrm{n}$ inhibits colony formation and migration of colorectal cancer cells. (A) In cell scratch test, a wound healing assay for migration by scraping cells with a yellow tip. The migration ability of RKO and DLD-I cells was evaluated by a scratch test. Compared with the negative control, cells treated with different concentrations $(10,20$, and $40 \mu \mathrm{M})$ of $3 \mathrm{n}$ showed that the cell migration was significantly slowed down with increasing concentration. Wound healing assay results from RKO and DLD-I were calculated. ( $* * P<0.01$, $* * * P<0.001$, $* * * * P<0.0001$ ). (B) For the colony formation assay, the number of colonies was counted 6-8 days after colorectal cancer cells were incubated and treated with various concentrations for $\mathbf{3 n}$, and DMSO (I $\mu \mathrm{L})$ was added as a negative control and then stained with crystal violet.

hrs, but had no effect on total STAT3 levels in the three cell lines. Moreover, incubation of HCT116 with a concentration gradient of $\mathbf{3 n}(10,20$, and $40 \mu \mathrm{M})$, HCT116, RKO, and DLD-1 cells significantly downregulated phosphorylated STAT3 expression in a dose-dependent manner (Figure 2B). These results indicate that the anticancer activity of $\mathbf{3 n}$ is mediated through the inhibition of
STAT3. As shown in Figure 2C, the results indicate that $3 n$, like the recognized role of the STAT3 inhibitor napabucasin, blocks IL6-induced activation of the STAT3 signaling pathway. We tested downstream protein levels of STAT3 and found that $3 \mathrm{n}$ also inhibits the expression of downstream target proteins, such as Survivin and MCL-1 (Figure 2D). 


\section{Discussion}

Colorectal cancer remains the leading cause of cancer deaths worldwide, despite extensive research and progress in screening and treatment. ${ }^{1,18,19}$ In addition, to date, there are no convincing agents that can significantly improve the survival rate of human colorectal cancer. ${ }^{5}$ STAT3 is considered to be an essential oncogene in the development of colorectal cancer and is thought to be carcinogenic in the development of colorectal cancer. ${ }^{20}$ In future studies, finding a suitable STAT3 inhibitor to inhibit abnormal activation of STAT3 in colorectal cancer cells remains a promising strategy to address this problem. ${ }^{21,22}$

In this study, we design of two new series of compounds with 2-amino-3-cyanopyridine chalcone and 3cyano-2-pyridinone skeleton chalcone. Three kinds of human tumor cells HCT-116, Hela229, and A375 were screened for biological activity against proliferation. The results showed that $\mathbf{3 n}$ can effectively inhibit the proliferation and migration ability of colorectal cancer cells. Further studies confirmed that STAT3 phosphorylation was inhibited in a time- and dose-dependent manner after exposure to $3 \mathrm{n}$. These results indicate that aminohydroxypyridine compound 3n can act as an inhibitor of STAT3, thereby inhibiting tumor growth and inducing apoptosis in colorectal cancer. $\mathbf{3 n}$ is a potent STAT3 inhibitor and may be a potential drug candidate for colorectal cancer therapy. Also, of course, $\mathbf{3 n}$ can also serve as lead compounds for optimization to speed the development of drugs selectively targeting the IL-6/STAT3 cancer signaling pathway. Additionally, the pharmacokinetics, pharmacodynamics, and toxicity of $\mathbf{3 n}$ will be further comprehensively evaluated. Combination therapy may enhance the curative effects and reduce the therapeutic concentration of chemotherapeutic drugs. ${ }^{23,24} \mathrm{We}$ also plan to investigate the combination of $\mathbf{3 n}$ and other clinical cancer drugs to improve the antitumor potency of $\mathbf{3 n}$ and verify its effect on colorectal cancer.

\section{Conclusion}

In summary, a novel series of cyanopyridines and aminocyanopyridines were designed, synthesized, and biologically evaluated. The most potent compound 3n exhibited remarkable inhibitory activity on HCT116, Hela, and A375 cells. Furthermore, 3n significantly inhibits cell colony formation and migration of colorectal cancer cells. Mechanistically, 3n decreased protein expression level of P-STAT3Y. Together, $\mathbf{3 n}$ is worth of further investigations toward the discovery of STAT3 inhibitor as a drug candidate for cancer therapy.

\section{Acknowledgments}

This work was financially supported by the Zhejiang Provincial Natural Science Fund (LY18H160047), National Natural Science Funding of China (21762006), Wenzhou Science and Technology Project (Y20190179), and Major Science and Technology Projects of Guangxi Zhuang Autonomous Region (No. AA17204090).

\section{Disclosure}

The authors report no conflicts of interest in this work.

\section{References}

1. Serrano PE, Carter DN, Li C, et al. Adjuvant chemotherapy with or without biologics including antiangiogenics and monoclonal antibodies targeting EGFR and EpCAM in colorectal cancer: a systematic review and meta-analysis. J Surg Res. 2019;239:14-21. doi:10.1016/ j.jss.2019.01.030

2. Valle L, de Voer RM, Goldberg Y, et al. Update on genetic predisposition to colorectal cancer and polyposis. Mol Aspects Med. 2019. doi:10.1016/j.mam.2019.03.001

3. Siegel RL, Miller KD, Jemal A. Cancer statistics, 2019. CA Cancer J Clin. 2019;69(1):7-34. doi:10.3322/caac.21551

4. Siegel RL, Miller KD, Jemal A. Cancer statistics, 2018. CA Cancer J Clin. 2018;68(1):7-30. doi:10.3322/caac.21442

5. Zhao CG, Li HM, Lin HJ, Yang SL, Lin JY, Liang G. Feedback activation of STAT3 as a cancer drug-resistance mechanism. Trends Pharmacol Sci. 2016;37(1):47-61. doi:10.1016/j.tips.2015.10.001

6. Caetano MS, Hassane M, Van HT, et al. Sex specific function of epithelial STAT3 signaling in pathogenesis of K-ras mutant lung cancer. Nat Commun. 2018;9(1):4589. doi:10.1038/s41467-01807042-y

7. Yu H, Lee H, Herrmann A, Buettner R, Jove R. Revisiting STAT3 signalling in cancer: new and unexpected biological functions. Nat Rev Cancer. 2014;14(11):736-746. doi:10.1038/nrc3818

8. Weinberg BA, Marshall JL, Salem ME. The growing challenge of young adults with colorectal cancer. Oncology (Williston Park, NY). 2017;31(5):381-389.

9. Yakubu UM, Morano KA. Roles of the nucleotide exchange factor and chaperone Hsp110 in cellular proteostasis and diseases of protein misfolding. Biol Chem. 2018;399(10):1215-1221. doi:10.1515/hsz2018-0209

10. Wang XY, Subjeck JR. High molecular weight stress proteins: identification, cloning and utilisation in cancer immunotherapy. Int $J$ Hyperthermia. 2013;29(5):364-375. doi:10.3109/02656736.2013.80 3607

11. Berthenet K, Bokhari A, Lagrange A, et al. HSP110 promotes colorectal cancer growth through STAT3 activation. Oncogene. 2017;36 (16):2328-2336. doi:10.1038/onc.2016.403

12. Krens SD, Lassche G, Jansman FGA, et al. Dose recommendations for anticancer drugs in patients with renal or hepatic impairment. Lancet Oncol. 2019;20(4):e200-e207. doi:10.1016/S1470-2045(19) 30145-7

13. Lauria A, Abbate I, Gentile C, Angileri F, Martorana A, Almerico AM. Synthesis and biological activities of a new class of heat shock protein 90 inhibitors, designed by energy-based pharmacophore virtual screening. J Med Chem. 2013;56(8):3424-3428. doi:10.1021/ jm4002023 
14. Gomha SM, Abdulla MM, Abou-Seri SM. Identification of novel aminothiazole and aminothiadiazole conjugated cyanopyridines as selective CHK1 inhibitors. Eur J Med Chem. 2015;92:459-470. doi:10.1016/j.ejmech.2015.01.019

15. Kalaria PN, Satasia SP, Avalani JR, Raval DK. Ultrasound-assisted one-pot four-component synthesis of novel 2-amino-3-cyanopyridine derivatives bearing 5-imidazopyrazole scaffold and their biological broadcast. Eur J Med Chem. 2014;83:655-664. doi:10.1016/j.ejmech. 2014.06.071

16. Dev S, Dhaneshwar SR, Mathew B. Virtual combinatorial library design, synthesis and in vitro anticancer assessment of -2-amino-3cyanopyridine derivatives. Comb Chem High Throughput Screen. 2018;21(2):138-148. doi:10.2174/1386207321666180228113925

17. Xu L, Qiu S, Yang L, et al. Aminocyanopyridines as anti-lung cancer agents by inhibiting the STAT3 pathway. Mol Carcinog. 2019; 58:1512-1525. doi:10.1002/mc.23038

18. ME IJ, Sanz-Pamplona R, Hermitte F, de Miranda N. Colorectal cancer: a paradigmatic model for cancer immunology and immunotherapy. Mol Aspects Med. 2019. doi:10.1016/j.mam.2019.05. 003
19. La Vecchia S, Sebastian C. Metabolic pathways regulating colorectal cancer initiation and progression. Semin Cell Dev Biol. 2019. doi:10. 1016/j.semcdb.2019.05.018

20. Gozzi GJ, Gonzalez D, Boudesco C, et al. Selecting the first chemical molecule inhibitor of HSP110 for colorectal cancer therapy. Cell Death Differ. 2019. doi:10.1038/s41418-019-0343-4

21. Kesselring R, Glaesner J, Hiergeist A, et al. IRAK-M expression in tumor cells supports colorectal cancer progression through reduction of antimicrobial defense and stabilization of STAT3. Cancer Cell. 2016;29(5):684-696. doi:10.1016/j.ccell.2016.03.014

22. Wei N, Li J, Fang C, et al. Targeting colon cancer with the novel STAT3 inhibitor bruceantinol. Oncogene. 2019;38(10):1676-1687. doi:10.1038/s41388-018-0547-y

23. Yang L, Lin S, Kang Y, et al. Rhein sensitizes human pancreatic cancer cells to EGFR inhibitors by inhibiting STAT3 pathway. $J$ Exp Clin Cancer Res. 2019;38(1):31. doi:10.1186/s13046-018-1015-9

24. Zheng H, Yang L, Kang Y, et al. Alantolactone sensitizes human pancreatic cancer cells to EGFR inhibitors through the inhibition of STAT3 signaling. Mol Carcinog. 2019;58(4):565-576. doi:10.1002/ mc. 22951

\section{Publish your work in this journal}

Drug Design, Development and Therapy is an international, peerreviewed open-access journal that spans the spectrum of drug design and development through to clinical applications. Clinical outcomes, patient safety, and programs for the development and effective, safe, and sustained use of medicines are a feature of the journal, which has also been accepted for indexing on PubMed Central. The manuscript management system is completely online and includes a very quick and fair peer-review system, which is all easy to use. Visit http://www. dovepress.com/testimonials.php to read real quotes from published authors. 